\title{
Lectotipificación de Limnocharis laforestii Duchass. ex Griseb. (Limnocharitaceae)
}

En 1858 A. Grisebach describió Limnocharis laforestii de una planta colectada en Panamá por E.P. Duchassaing en 1850. En la descripción hecha por Grisebach y publicada en Bonplandia VI: 11., bajo el título de Novitae Florae Panamensis, el autor no designó ejemplar alguno como tipo.

Según Urban (1898) y Stafleu y Cowan (1976), las colecciones realizadas por Duchassaing en las Antillas y Panamá, se encuentran depositadas en GOET, a través de Grisebach, aunque un buen número de ellas se encontraban también en $\mathrm{B}$, las cuales se perdieron durante la segunda guerra mundial y algunas otras están depositadas en P.

$\mathrm{Al}$ obtener en préstamo las colecciones tanto de GOET como de $\mathrm{P}$, resultó que en el herbario GOET están depositados dos ejemplares marcados como tipos pertenecientes a esta especie.

Uno de los ejemplares depositados en el herbario GOET, presenta un dibujo original realizado por el propio Duchassaing en acuarela donde se ilustra una hoja y una inflores-

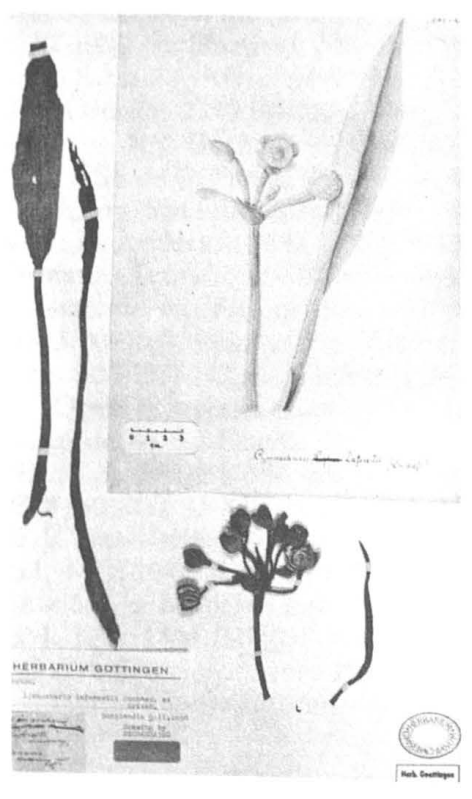

Fig. 1. Limnocharis laforestii Duchass. ex Griseb. Lectotipo designado del herbario GOET. 
cencia. Este ejemplar presenta además en el lado izquierdo e inferior de la cartulina varias hojas y una inflorescencia en distinto estado de desarrollo (desde flores hasta frutos y semillas maduras). En la esquina inferior izquierda hay una pequeña etiqueta escrita a mano (probablemente hecha por Grisebach), en la cual se observa "Limnocharis laforestii duchassaing. Panama duchassaing misit 1850". Estos datos nos indican que precisamente este fue el ejemplar enviado por Duchassaing y es el que se designa aquí como lectotipo (fig. 1).

El segundo ejemplar de este mismo herbario presenta una hoja y dos inflorescencias y también un dibujo original en acuarela, aunque el dibujo es claramente diferente al que hemos designado como lectotipo tanto en los colores usados como en el trabajo realizado. Este segundo ejemplar no presenta etiqueta con los datos de colecta, por lo cual es difícil determinar si se trata de un duplicado u otra colección.

Por lo que respecta al ejemplar depositado en el herbario P, éste presenta una etiqueta del propio Museo de París pero con la diferencia en relación al ejemplar de GOET, de que tiene fecha de 1851. Esta colecta aunque proviene de Panamá, es difícil asegurar si es un duplicado del ejemplar depositado en GOET o pertenece a otra colección realizada por el mismo Duchassaing.

AgradecimiEntos. Quiero agradecer al Dr. Alfonso Delgado, del Instituto de Biología de la UNAM, la revisión y los comentarios hechos al presente trabajo, así como al Dr. Fernando Chiang, también del Instituto de Biología de la UNAM, por la ayuda prestada para entender algunas palabras en latín. Este trabajo se realizó con apoyo del proyecto PCECBNA 021697 auspiciado por el CONACYT.

\section{LITERATURA CITADA}

GrisebaCh, A. 1858. Novitae Florae Panamensis. Bonplandia VI:2-12.

Stafleu, F.A. y R.S. Cowan. 1976. Taxonomic literature 2a. ed., Utrecht I:689.

Urban, I. 1898. Symbolae Antillanae. Berolini, Fratres Borntraeger. I:39, 56.

Alejandro Novelo R., Departamento de Botánica, Instituto de Biología, Universidad Nacional Autónoma de México, Apdo. Postal 70-233, 04510 México, D.F. 